\title{
Examining the Effective Rate of Environmental Qualities on the Security of Citizens in Urban Designs Using AHP Model (Sepah and Molavi Districts in Qazvin City of Iran)
}

\author{
Mohammadreza Sadeghi Moghadam ${ }^{1, *}$, Neda Rajabi ${ }^{2}$, Fatemeh Zolghadr ${ }^{2}$, \\ Kourosh Palad ${ }^{2}$, Salameh Azimi $^{3}$ \\ ${ }^{1}$ Department of urban planning, Qazvin Branch, Islamic Azad University, Qazvin, Iran \\ ${ }^{2}$ B.A Student of Urban Planning, Researcher of Construction Industry Research Center of Qazvin Islamic Azad University \\ ${ }^{3}$ Faculty of Industrial and Mechanical Engineering, Qazvin Branch, Islamic Azad University, Qazvin, Iran \\ *Corresponding Author: m.sadeghi62@gmail.com
}

Copyright () 2014 Horizon Research Publishing. All rights reserved.

\begin{abstract}
To date, the necessity of security has always been felt in human lives and is one of the most basic human needs. On the other hand, urban space has the highest correlation with people and life environment and therefore it has an important role in giving identity and relaxation to citizens. Nowadays, paying attention to the concept of citizen's security and using various methods to promote are the main concerns of urban designers and authorities. Therefore, establishing a safe city by using efficient urban designs are resulted in environmental aesthetics, improving the quality of city framework and reducing urban crimes in addition to social, cultural and psychological impacts. The present study sought to identify effective environmental quality criteria on security such as accessibility, urban furniture, light and lighting designs, the role of pedestrian in addition to analyzing them and doing important factor of criteria using Analytical Hierarchy Process (AHP) model of weighting. Finally, two cases (Sepah and Molavi districts) were evaluated according to these criteria in terms of security. The results of the present study indicated that urban space design associated with presenting desirable environmental quality has a direct correlation with the security of citizens.
\end{abstract}

Keywords Urban Space, Urban Security, Environmental Quality, AHP Model, Urban Design (Defensible Space)

\section{Introduction}

As a home brings convenience and safety to family members, the city and its space should provide comfort and security for its residents. Actually, the presence of security in city framework is a necessary affair which needs the attention of municipal authorities. Creating an appropriate relationship between residential areas and neighborhoods, protecting and observing abandoned and haunted places decrease committing crime possibility. Moreover, the availability of welfare equipment and facilities such as public telephones, police shelter in empty places result in improving the feeling of accessing to help among people. One factor which leads to security promotion is environmental quality and designing the city framework. City builders and urban designers can bring citizens together using creating desirable city space and friendly public spaces and can greatly decrease insecurity.

Space building, creating efficient activities in empty or less traffic places and public monitoring of insecure places have effective roles in the security of citizens. The present approach provide the possibility to create safe and secure places for citizens with improving environmental qualities including walkway design, city furniture, lighting, landscape and community centers. On the other hand, insecure places are those places which are hidden from view of people and/or have favorable conditions for committing crimes. Therefore, committing urban crimes and increased insecurity can be avoided with identifying qualitative factors of effective urban design on urban space security.

In the present study, gathering data tools and used references are considering and studying available books and papers in the field of researching and also gathering urban expert viewpoints which hereby will identify the criteria of effective environmental quality on security and will prioritize and weighting using the ADH model. The present study tries to utilize the role of environmental quality in urban design and creating relationship between constructed spaces and factors such as appropriate lighting, urban furniture, the role of pedestrian, public places and access 
design which have tremendous impact on psychological security of residents of cities and consider the effect of these factors on the security of citizens in two districts of Sepah and Molavi in Qazvin, Iran.

\section{Definition of Security}

Crime and the fear of crime are endemic concerns in contemporary urbanized societies. Crime Prevention through environmental design (CPTED) is a branch of spatial practices that looks at Interventions focused on place-based strategies for reducing crime, and the enhancement of spatial cognition as it relates to the perception of safety and security (united nations interregional crime and justice Research Institute (UNICRI), 2011).

The concept of security can be defines as immunity from attack and mandatory takeover without consent, being immune to the treat and be protected from the risk of death and totally, any factor which eliminates human comfort (Afshani and Zakeri Hamaneh, 2012).This word encompasses an extent range of definitions and characteristics about urban areas, but its importance has never been decreased in city building literature. Security, as it is considered in the present study, is a psychological concept and is derived from the conditions of environmental framework. This security has both mental aspect and objective (outer) aspect.

Mental aspect: is sense of peace, confidence and release from any kinds of fear, threat, and panic in urban public fields

Objective (outer) aspect: also includes protecting the security of pedestrians against automobiles. Actually, security is more an inner feeling than an outer index. The feeling of individual and public security includes security indicators (Daneshpour and Fakhari, 2011).

\subsection{Urban Security and Defensible Spaces}

Urban security means tranquility, confidence and the absence of citizens' fear of any kinds of threat and danger against the city, citizens, urban space, buildings, installations and urban infrastructures and other important elements in urban life which causes worry and insecurity in citizens (Daneshpour and Fakhari, 2011).

The theme of 'urban safety and security' encompasses a wide range of concerns and issues. These range from basic needs, such as food, health and shelter, through protection from crime and the impacts of technological and natural hazards, to collective security needs, such as protection from urban terrorism or war (United nations human settlements program (UN-HABITAT), 2007).

Defensible space is a design concept consisting of four features: the definition of space which demarcates areas of influence of the inhabitants and creates territorial attitudes, the positioning of windows to allow natural surveillance of public areas, the adoption of building forms and idioms which avoid the stigma of peculiarity and the suggestion of vulnerability, and the location of developments away from areas that provide continued threat (Merry, 1981).

- Defensible Space relies on self-help rather than on government intervention, and so it is not vulnerable to government's withdrawal of support.

- It depends on resident involvement to reduce crime and remove the presence of criminals.

- It has the ability to bring people of different incomes and race together in a mutually beneficial union (Newman, 1996).

Moreover, various viewpoints have been expressed for defining defensible spaces which are discussed briefly:

- Urbanism culture considers that the defensible space is the spatial residents of neighbor buildings that have the ability to monitor and control it.

- Broadbent believes that defensible space can be controlled where everyone has the potential of crime and can be seen by residents as a nuisance.

- Carmona stated that the idea of defensible space is the physical environment surrounding the reduction of criminal behavior that is effective in reducing fear of crime. So perhaps the defensible urban space can be defined as spaces in the city that is less capable for acts of crime and abnormal abuses (Parto and athers, 2013).

Nowadays, many people try to increase security and protect their lives and properties with creating even minor changes such as leaving even a little light on in the environment of their lives.

In this regard, urban designers can play important roles in prevention of committing crimes. Urban designers can create robust spaces against crimes and also prevent committing many crimes with identifying crime generating areas in cities and also with planning and appropriate designing.

\subsection{The Role of Security in Having a Satisfying Life}

Establishing convenience and comfort of the public and according to conditions, facilities, sources and also shortages, shortcomings in cities, areas, and districts of cities are necessary for having a satisfying life. In this regard, security has a significant place since life and life sustainability assurance will be achieved in the shadow of security. Urban securities result in the convenience of people and it allows life affairs in their natural contexts. Actually, security is prerequisite for life and urban life, if the cities had higher safety coefficient, more social communications, cultural and economic relations would be occurred and in contrast, cities with lesser safety coefficient more fearful people and level of interactions and exchanges will be decreased and damaged (Navidnia, 2010).

\section{The Concept of Environmental Quality and the Effect of Its Indicators on the Security of Citizens}


Quality is one of the basic concepts of knowledge, profession and urban design and it naturally has great practical and theoretical significance. The quality topic in terms of practical has also become one of the most serious questions in addition to theoretical importance, which currently most urban environments are faced with it due to the quality crisis (Golkar, 2000).

In fact, "environmental quality" can be one of the most important concerns of urban designing knowledge. It is such that many theorists know "promoting environmental quality" as the most important active duty of urban design (Pakzad, 2006).

Therefore, whatever is added to the desirability amount of environment, social interaction are formed in a specific framework and give identity and value to public space. Reciprocal relationship and the effect of "urban designing quality" on "life quality" of residents of cities have been emphasized by Kevin Lynch. He says "If urban design is going to be useful, it should be able to assist promoting "life quality" of human being through promoting "quality framework of environment" (Golkar, 2000).

One of the other emphases on urban environment is the availability of designing considerations in the field of promoting the quality of connections (streets, porches, walkways) and places (squares, parks, roofs) since the quality of places and connections are related to creating sense of security and even giving the sense of value to oneself and also being a member of a valuable community. Quality is related to aesthetics, forms and lighting of one place, the activities and people who participate in it (Zadegan and Vahidian, 2009).

Hence, the present study considers some qualitative components of environment in which creating the security of citizens has a significant effect and can have effective roles in establishing satisfied lives and relaxed environment.

\subsection{Light and Lighting}

Light is one of the most important qualitative and symbolic factors which have a special position in architecture and urban planning in terms of practical. Light is one of the main elements of urban landscape that urban designers should pay more attention to its role in supplying urban security and its preventing role in committing crimes. Lighting defines identity and urban landscape at night and the absence of light and the existence of darkness at night causes complications such as increased events, accidents, crimes, delinquency, and decreased social security (Etemadi Far, 2008).

Nowadays, urban life caused many activities to continue late at night. Therefore, urban designers must think about light element not just as a decorative element but also as an advanced method in providing more security and tranquility for environment in order to prevent committing crimes. Actually, light causes security increasing in crowded places since it makes the space defensible and lessen the possibility of indecent acts and violations. An example of lighting at night is shown in Fig.1.

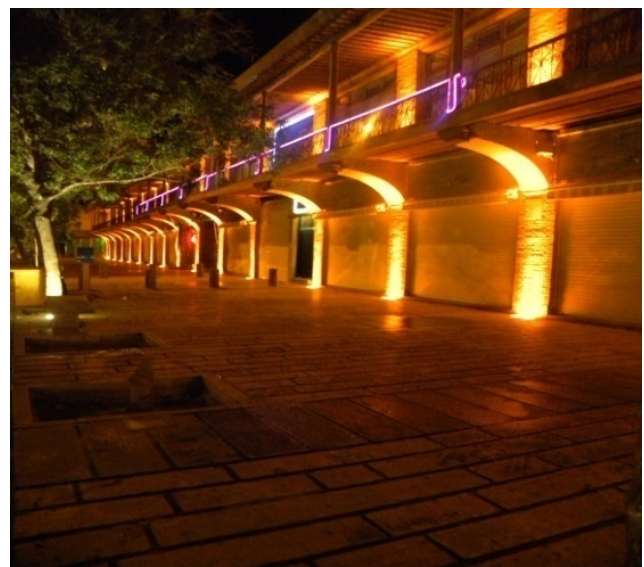

Figure 1. light and lighting at night cause more security for citizens (Sepah district, Qazvin, Iran)

\subsection{Urban Furniture}

Urban furniture is one of the proposed elements in urban planning and designing and as a part of the whole city can defines identity and urban structure.

Appropriate designing of urban furniture and using them in accordance with different environments result in the presence of all segments of the society (men and women, old and young, disabled and etc.) and their more interactions in their environment, society and ... at all hours of day and night which indicate in preventing committing crimes and increasing security and tranquility of citizens. If the furniture of an environment is not arranged or their elements do not have visual attractions, people feel confusion and insecurity when they sit on them and they themselves are driven from that place. Therefore, urban designers must create a secure and desirable environment through appropriate use and correct arranging of elements. Fig.2 shows a suitable urban furniture in Sepah district.

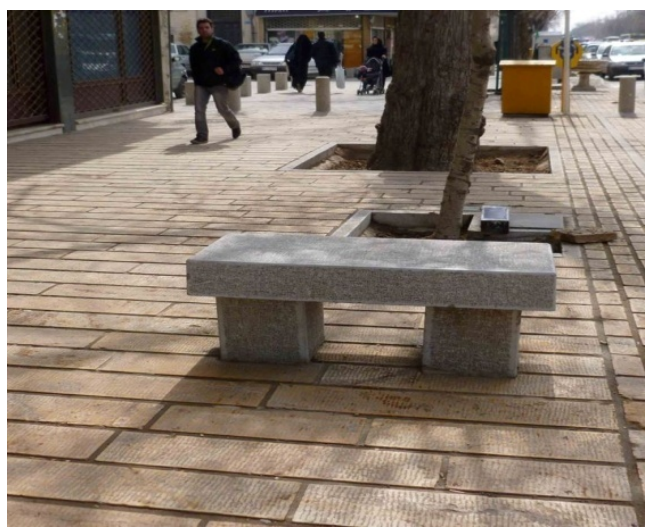

Figure 2. An example of urban furniture in Sepah distict, Qazvin, Iran.

\subsection{The Role of Pedestrian}

Another important factor in urban design is pedestrian role. Since roadway has priority in current design, the adults 
feel threatened and insecure in this position. If pedestrian design was in the second priority, the sense of identity and intimacy will lost and people will become a stranger. Required facilities for pedestrian include roadways, traffic and relaxation control devices and urban furniture that some issues such as creating appropriate routes for pedestrian movement, paying attention to pedestrian needs in all transportation facilities, increasing security and pedestrian traffic, appropriate pavement of pedestrian corridors in order to increase pedestrian security, efficient protecting designs of lands and transportations in which pedestrian facilities have been mentioned and removing available barriers in walkways needs special attention in designing above mentioned cases in order to encourage citizens to walk. Generally, it can be said that urban designer must use solutions in order to create secure and acceptable environments for citizens. Moreover, some policies can be determined for designing space which leads to promotion of urban district. Fig 3 shows an example of wide walkway and suitable urban furniture's in Sepah district, which cause more security for pedestrians but unfortunately as it shown in fig.4, because of not having suitable urban furniture's and too narrower walkways in Molavi district makes insecurity for pedestrians.

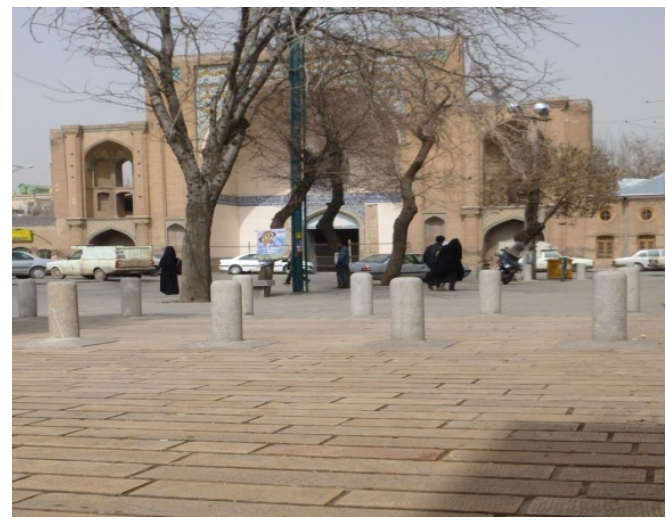

Figure 3. Sepah district walkways, Qazvin, Iran.

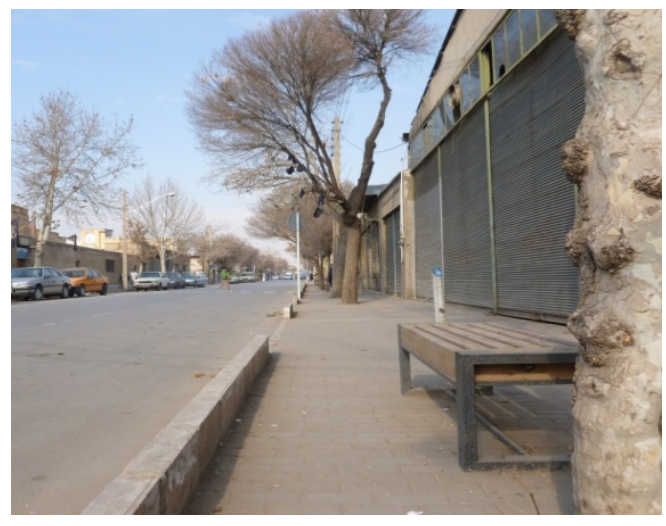

Figure 4. Molavi district walkways, Qazvin, Iran

\subsection{Public and Green Space}

Public and general places have always been places for spending free time. The design of these spaces must be in a way which firstly be useful for all segments of the society, and secondly the pedestrian has the priority of using the space than the other people. When public places are the traffic places for those who are not on foot such as motorcyclists, the rate of disorders and committing crimes such as stealing purse and attacking pedestrians will be increased and tranquility and security of citizens will be in danger. In addition, these issues are needed: playgrounds for children and amusement parks should have enough vision from different sides, specific ad determined privacy should be put between public and private spaces, characteristic elements should be more visible in public places and playgrounds in order to increase the readability in environment and decrease confusion, utilizing appropriate lighting and putting lighting lamps in close distances increase the sense of vitality and mobility in environment, adequately monitor the corner locations and places far from public sight, preventing the entry of vendors and false job into the parks and public places and vegetative covering and surrounding walls of the parks must be short to not obstruct the public vision and not make a place for committing crimes.

\subsection{Access Design}

As we know, urban accesses, roads and passages are considered as most important urban spaces so that almost $25 \%$ to $35 \%$ of the municipal budget is allocated to passages and connected network design. Passages are considered as places for moving people and transportations, so, the security of citizens while traveling is an issue to which should special attention should be paid. Therefore, effective factors on decreasing crimes and increasing security will be addressed with considering walkway and crossing roadway design.

\subsubsection{Pedestrian Thoroughfares}

One of the factors which promote security in space is the quality of road network. Walkways are considered as places for interactions and presence of citizens in their lives.

Designing paths correspond with walking in a city structure. Is essential because of these reasons that it belongs to every ones who are in the city and need flexibility various types of activities and spaces providing safety and security and sense of belonging to the space that finally promote the quality of path promotion of social relations and the prosperity of city life(Songhai Asl, 2012).

Creating pause spaces in walkways, using appropriate flooring, beautiful floriculture around the walkways, resolutions through the road especially at night, removing annoying efficiencies through walkways, utilizing paintings and graphical shapes for beautification walkway space and ... result in encouraging citizens to walk and decreasing their intentions to use transportation vehicles in order to traverse short paths. The rate of social, dynamic and lively interaction are increased in accordance with increased 
presence of citizens in walkways and pause spaces and therefore, their security promotion will be followed.

\subsubsection{Crossing Roadways}

The trend of urbanization and city expanding caused limitless development of city. City development also caused extended passages. Meanwhile, crossing roadways have significant roles in establishing a relationship among different spaces and are considered one of the main elements of communications in city.

Performance of the road network of each city is an important criterion in its economic growth so that cities of developed societies have efficient transportation network. Among performance evaluation criteria of transportation network is its safety index. Safety criterion in road network has an important role in the rate of network reliability (Malihi, 2011).

Utilizing some principles in designing and controlling crossing roadways such as accurate definition of entries and exits, citizen and pedestrian monitoring on the access paths, controlling outlying and less traffic roads by officers, placing lighting lamps in surrounding passages and near each other can greatly decrease the rate of committing crimes. Moreover, accurate and ordered design of alleys and residential areas like dead-end result in: first, thieves and criminals do not use these accesses as shortcut roads during escape, second, strange people less enter the street and residents have more recognition and familiarity of each other.

\section{Method}

Since the subject of the present study is about considering the rate of effectiveness of environmental quality on security in urban space design, criteria and indicators of environmental quality which are effective on security were determined according to library studies and available theoretical basics in this field in the first stage, then criteria were prioritized and weighted by using urban experts and Expert Choice software and two samples of Sepah and Molavi of Qazvin were analyzed by these criteria.

\subsection{Concept Framework of Analytical Hierarchical Process}

Analytical Hierarchical Process starts with identification and prioritization of elements of decision: these elements include goals, criteria or indicators, and possible options which are used in prioritizing. The process of element identification and the relationship among them result in creation of a hierarchical structure: the reason of making hierarchy is that the elements of decision can be summarized in different levels, so, the first stage in Analytical Hierarchical Process is to create a hierarchical structure of the considered subject in which goals, criteria and options and the relationship among them are represented. Next four stages in Analytical Hierarchical Process include the calculation of the weight factor, criteria and the following criteria, and the weight calculation of option factor (calculation of final score of options and consideration of logical consistency of judgments). The model potency and quantifying the qualitative indicators can be known among the reasons of using this model instead of other models because the previous models do not have this ability. Moreover, collective and collaborative ideas can be used in addition to using statistics and figures in this model which are among important reasons of using this model in the present study (Ghalibaf and Shabani Frad, 2011).

According to the mentioned description and the purpose of the present study, the weight of important factor of each identified criterion and indicator were determined based on comparison of criteria with each other through the scale of 9-hourly quantity for binary comparison of options and the following results are indicated Analytical Hierarchical Process (AHP) and Expert Choice software (Table 1)

Table 1. The scale of 9-hourly quantity for binary comparison of options

\begin{tabular}{|c|c|c|c|c|c|c|}
\cline { 2 - 7 } \multicolumn{1}{c|}{} & Light and Lighting & Public Spaces & The role of Pedestrian & Urban Furniture & Access design & priority \\
\hline Light and Lighting & 1 & 2 & 3 & 5 & $1 / 2$ & 0.259 \\
\hline Public space & $1 / 2$ & 1 & 2 & 4 & $1 / 3$ & 0.160 \\
\hline The role of Pedestrian & $1 / 3$ & $1 / 2$ & 1 & 1 & $1 / 3$ & 0.096 \\
\hline Urban Furniture & $1 / 5$ & $1 / 4$ & $1 / 3$ & 7 & $1 / 7$ & 0.046 \\
\hline Access design & 2 & 3 & 5 & 1 & 0.440 \\
\hline
\end{tabular}

Table 2. The Analysis of samples related to the criteria indicators Case Study

\begin{tabular}{|c|c|c|c|c|c|c|}
\hline & Light and Lighting & Public Spaces & The role of Pedestrian & Urban Furniture & Access Design & final priority \\
\hline Sepah Street & $1 / 3$ & $1 / 3$ & 2 & 4 & 5 & 0.560 \\
\hline Molavi Street & 3 & 3 & $1 / 2$ & $1 / 4$ & $1 / 5$ & 0.440 \\
\hline
\end{tabular}




\subsection{Case Study}

Sepah Street which is 400 years old is one of the most important and the most valuable old streets of Qazvin which is the first city of Iran because of the instruction which is related to Safavid period; it is known as the oldest street of Iran. This street was proposed as a street with resort performance in the initial construction which had governmental function such as levee ceremonies, reading the instructions and governing rules and etc, in addition to having social position. Nowadays, although the most performance of the framework is commercial and important and valuable buildings are located in the vicinity,

It has lost its recreational performance. Proximity to cultural garden collection, bazaar, Immamzadeh Hussein and old districts create a special feature for making original and secure urban spaces.

Molavi Street is considered as old and historical axis of Qazvin. This street is connected to bazaar and is place in south area of Qazvin and has old substructures. Most framework of its surrounding is commercial there are some entries from this street to bazaar.

Two samples were analyzed according to mentioned criteria in the present study and the results are as follows (Table 2).

\section{Conclusion}

At first criteria and indicators of environmental quality which are effective on security were prioritized in Expert Choice in the present study. Then, Sepah and Molavi districts were analyzed related to these criteria. After the assessment was made, it was found that Molavi district has numerous problems than Sepah and the sense of security is lesser.

According to the process of the present study, it is quite clear and obvious that environmental qualities in urban space design have close relationships with creating security in urban space and citizens. Lighting in narrow and hidden passageways and also creating light at night, standard, accurate and arranged design of accesses, pedestrian priority over cars in local roads, construction of a small square in local intersections, changing wastelands and faraway lands into public open space and green space, impalpable care of crime locations, changing useless performances into active performances, constructing landscapes, using indexed elements in arranging urban furniture, and repeating these elements in space are factors of environmental design which affect the security of citizens. On the other hand, security is considered as a primary and basic need of each person and municipal authorities are responsible for providing it in the range of urban space that city builders and urban designers by providing appropriate urban environment and friendly space through urban design and represent their effective roles in this field can be so effective.
Therefore, modern cities are analyzed according to various criteria of development and their progressive rates are tested. On the other hand, according to the rapid growth of urban areas, qualitative patterns of urban design are less considered by designers and manufacturers in order to obviate various needs of citizens such as the sense of tranquility and security in life space (urban space). Therefore, in order to solve this problem and promote the

Security of citizens, effective environmental qualities must be improved that improving accessible network design can be mentioned as one of the most important of them.

\section{REFERENCES}

[1] Afshani.A, Zakeri.H. (2012). A comparative study of social security sense of women and men living in Yazd. Woman in Development and Policy, 10, 3.

[2] Daneshpour.A, Fakhari.S. (2011). Confronting Crimes in urban space using urban designing tools. Golestan Journal.

[3] Enhancing urban safety and security. (2007). United Nations Human Settlements Programme (UNHABITAT), Global report on human settlements, Abridged Edition, 2.

[4] Etemadi Far.A. (2008). The role of urban lighting and lighting design in the security of citizens. Selected Articles of the Second Community Conference.

[5] Ghalibaf,B. Shabani Frad,M. (2011). Evaluating and prioritizing tourist attractions for developing urban tourism according to multivariate decision models. Journal of Geographical Research, (101), 2011.

[6] Golkar, K. (2000). Constructive elements of urban designing quality. ScientificResearch Journal of Soffeh, 32, 3865.

[7] Improving urban security through green environmental design new energy for urban security. (2011), United Nations interregional crime and justice Research Institute (UNICRI), available at http://www.unicri.it/.

[8] Malihi, V. (2011). Considering the relationship among passageways, traffic, and urban traffic with psychological security of city. Graduated from Urban Planning.

[9] Merry, E. Defensible, S. Space Undefended: Social Factors in Crime Control Through Environmental Design. Urban Affairs Review 16:397, DOI: 10.1177/107808748101600401, 1981.

[10] Navidnia, M. (2010). Security priority of citizens in different districts of Tehran. Scientific Research Journal of Human Geography, 2, 2.

[11] Newman, O. (1996). Creating Defensible Space by Oscar Newman (Institute for commynity Design Analysis).

[12] Pakzad, J. (2006). Theoretical principles and urban design process. Department of Housing and Urban Development, 1.

[13] Parto, S.H. Palizi, K. Dadras, R. (2013). Providing the Design Criteria to Achieve Defensible Space Using the Urban Design Methods, J. Basic. Appl. Sci. Res., 3(1)10081014. 
[14] Saghafi Asl.A, Haghlesan.M, Abdollahzadeh Taraf.A. (2012). The role of pedestrian streets in sustainability of urban spaces, case study: Tabriz Tarbiyat Street, Iran. Advances in Natural and Applied Sciences, 6(6): 10141021.

[15] The First International Lighting Conference of Tehran, Light Architecture Office, Light in Tehran, 2008.
[16] Zadegan, A. Vahidian, R. (2009). Strategic design of processoriented and productcentric of urban environmental qualities. Scientific Research Journal of BagheNazar. 12, 316. 